\title{
Determining characteristics of HF communications links using SuperDARN
}

\author{
J. M. Hughes ${ }^{1}$, W. A. Bristow ${ }^{1}$, R. A. Greenwald ${ }^{2}$, and R. J. Barnes ${ }^{2}$ \\ ${ }^{1}$ Geophysical Institute, University of Alaska Fairbanks, Fairbanks, AK, USA \\ ${ }^{2}$ Applied Physics Laboratory, The Johns Hopkins University, Laurel, Maryland, USA
}

Received: 1 October 2001 - Revised: 18 February 2002 - Accepted: 5 March 2002

\begin{abstract}
Space weather effects can strongly influence high-frequency (HF) communications by changing the ionospheric environment through which the radio waves propagate. Since many systems utilize HF communications, the ability to make real-time assessments of propagation conditions is an important part of space weather monitoring systems. In this paper, we present new techniques for measuring high-latitude HF communications link parameters using data from SuperDARN radars. These techniques use ground-scatter returns to define the variation in skip distance with frequency. From these data, the maximum usable frequency (MUF) as a function of range is determined and ionospheric critical frequencies are estimated. These calculations are made in near-real-time and the results are made available on the World Wide Web. F-region critical frequencies calculated using this method show good agreement with ionosonde data.
\end{abstract}

Key words. Ionosphere (active experiments; instruments and techniques) - Radio science (ionospheric propagation)

\section{Introduction}

The University Partnering for Operational Support (UPOS) project is a collaborative effort between The Johns Hopkins University Applied Physics Laboratory and the Geophysical Institute at the University of Alaska Fairbanks. UPOS began in 1998 with the goal of developing operational tropospheric and space weather data products for the Air Force Weather Agency. UPOS includes tropospheric weather products such as volcanic ash trajectory forecasting and an atmospheric profile generator, and space weather products such as real-time estimations of $K_{p}$ and auroral oval positions, and predictions of geomagnetic activity and storms.

The term "space weather" refers to relatively rapid changes in the Sun-Earth environment (including the solar wind, magnetosphere, and ionosphere). The importance

Correspondence to: J. M. Hughes (hughesj@gi.alaska.edu) of accurately forecasting and nowcasting space weather increases as human activity becomes more dependent on technology that is sensitive to its effects. As an example of such a technology, high-frequency (HF) radiowave communications are strongly influenced by space weather. The reason for this is that the state of the ionospheric medium through which they propagate is continually changing in response to space weather conditions. Ionospheric effects of space weather can include sudden changes in the spatial structure and density of the D-, E-, and F-regions. These changes then affect HF radiowave propagation by altering parameters such as the maximum usable frequency (MUF) over HF communications links. Since HF communications are used in a wide variety of applications including defense, emergency services, and marine and aviation operations, making accurate real-time measurements of high-latitude HF propagation conditions is an important part of space weather monitoring systems.

In this paper, we will discuss UPOS data products that are being developed at the Geophysical Institute designed to monitor these high-latitude propagation conditions using real-time data from the Super Dual Auroral Radar Network (SuperDARN). After describing the SuperDARN instrumentation and radar operating mode, we will discuss a new technique for making near-real-time measurements of MUF over high-latitude HF propagation circuits. This will be followed by a discussion of a technique currently being developed that provides near-real-time estimates of ionospheric critical frequencies. Finally, we summarize our work on this UPOS data product and discuss future modifications.

\section{Instrumentation}

A complete description of the SuperDARN instrumentation is given by Greenwald et al. (1985, 1995), so only a brief overview will be given here. SuperDARN is a network of HF coherent scatter radars designed for the purpose of investigating the structure and temporal evolution of plasma convec- 

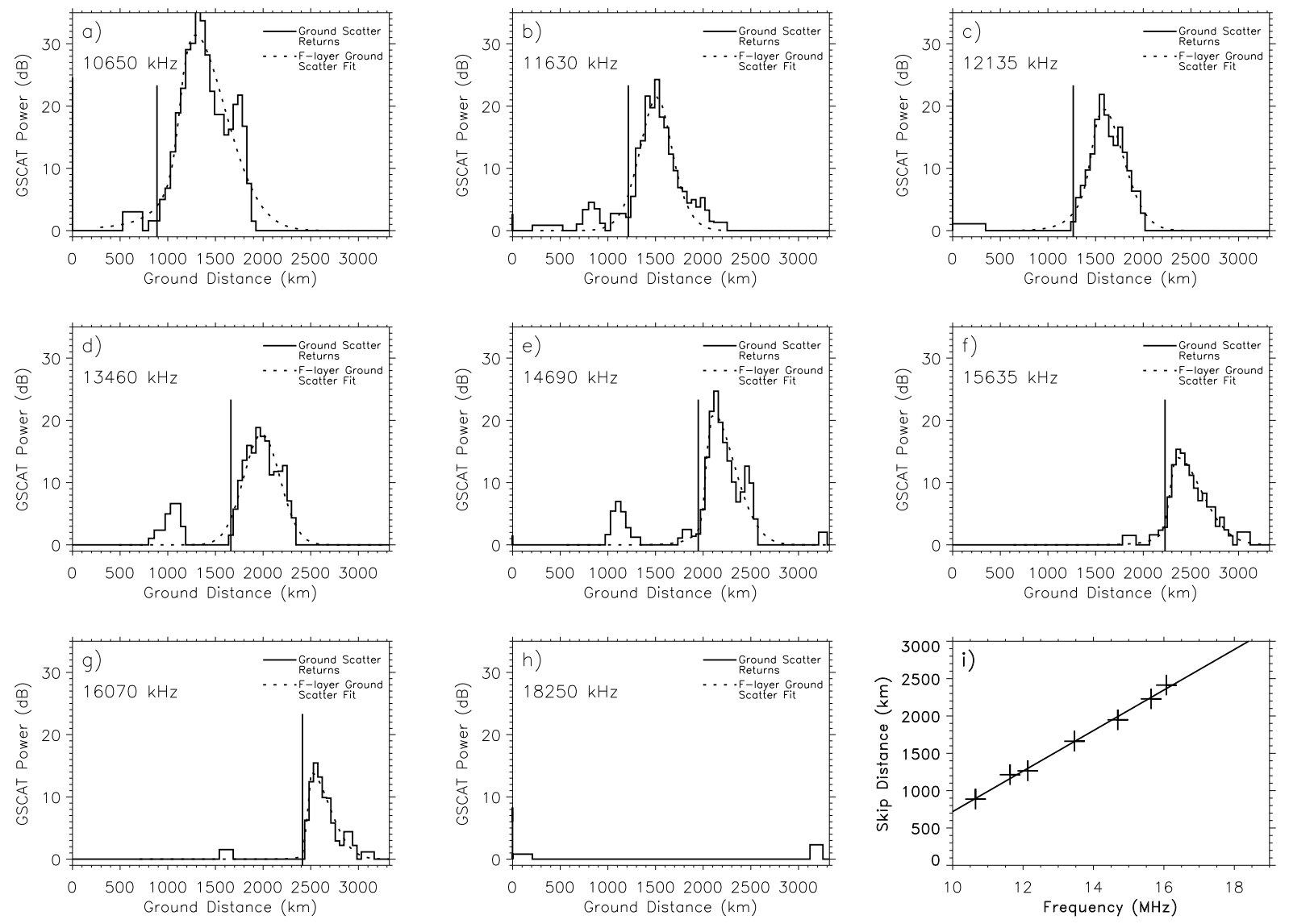

Fig. 1. (a)-(h) Ground-scatter as a function of range from the Kodiak SuperDARN radar observed on 23 June 2001 between $22: 40$ and 22:55 UT. The solid vertical lines in each panel show the F-region skip distance. (i) F-region skip distances identified in (a)-(h) plotted as a function of frequency. The solid line is a linear least-squares fit to these data.

tion in the high-latitude ionosphere (Ruohoneimi et al., 1989; Ruohoneimi and Baker, 1998). Although this is the main purpose of the network, data from SuperDARN radars have been used to study a wide variety of ionospheric and magnetospheric phenomena including, for example, ULF pulsations, atmospheric gravity waves, and field line resonances (e.g. Walker et al., 1992; Samson et al., 1990; Bristow and Greenwald, 1996; Ruohoneimi et al., 1991; Samson et al., 1992). Each SuperDARN radar operates in the $8-20 \mathrm{MHz}$ frequency interval and uses a phased-array antenna to scan a $52^{\circ}$ azimuth sector with 16 evenly-spaced narrow $\left(\sim 4^{\circ}\right.$ wide $)$ beams. The radars typically perform 1- or 2-min scans, using data integrated for 3 or $6 \mathrm{~s}$ per beam (for 1- or 2-min scans, respectively) to measure quantities such as the backscattered power, Doppler velocity, and spectral width as a function of range along each beam direction. At each SuperDARN site, azimuth scans begin on a whole minute boundary and are synchronized to other SuperDARN sites by a Global Positioning System (GPS) clock.

Since scans are synchronized on whole minute boundaries, typically there are about $12 \mathrm{~s}$ per min during which no data are collected. We have developed a radar operating mode known as the "sounding mode" that makes use of these $12 \mathrm{~s}$ to collect data useful for space weather studies. For each site operating in the sounding mode, a table of frequencies is defined that typically consists of approximately 8 entries equally spaced between 10 and $18 \mathrm{MHz}$. During the time available between azimuth scans, the sounding mode steps through this frequency table for each beam direction using $1 \mathrm{~s}$ integration periods. Since only $12 \mathrm{~s}$ per minute are available to this mode, a full scan at each frequency is completed only after a number of regular azimuth scans. The amount of time required to record a full sounding mode scan varies with the number of frequencies but is typically in the range $10-15 \mathrm{~min}$.

The techniques presented in this study benefit from two valuable features of SuperDARN. First, the combined fieldof-view of all SuperDARN radars covers a significant fraction of the high-latitude ionosphere (see, for example, Fig. 1 from Shepherd and Ruohoniemi, 2000), making it possible to monitor propagation conditions over much of this area. Second, the real-time availability of data from many SuperDARN radars makes it possible to continually monitor these conditions and provide current information about space weather effects. 


\section{Space weather products}

SuperDARN radars observe backscattered signals from at least three distinct sources: decameter-scale ionospheric irregularities, ionospheric meteor trails, and ground reflections (or ground-scatter). The techniques described in this paper make use of ground-scatter returns observed in the sounding mode. Ground-scatter returns occur in SuperDARN data when signals transmitted by the radar are reflected first by the ionosphere and then by the Earth's surface, with some fraction of the signal power undergoing backscatter and returning to the radar after another ionospheric reflection. In contrast to the other types of backscatter, ground-scatter returns are identified by their characteristic low Doppler velocity and low spectral width.

\subsection{Maximum usable frequency}

Before describing our technique for determining MUFs, it will be useful to discuss a few basic aspects of ionospheric radio-wave propagation. For this purpose, it is appropriate to consider the simple case of a radiowave propagating in an unmagnetized, horizontally stratified, single layer ionosphere. From geometric optics, it is known that rays at a frequency $f_{0}$ will be reflected by the ionosphere if the condition

$\theta_{0} \leq \cos ^{-1}\left(1-f_{c}^{2} / f_{0}^{2}\right)^{\frac{1}{2}}$

is met, where $\theta_{0}$ is the takeoff angle measured from the horizontal and $f_{c}$ is the ionospheric critical frequency. Rays with a takeoff angle not meeting this condition will penetrate the ionosphere and be lost into space. For reflected rays, as the takeoff angle increases, the ground range to the reflection point decreases and the reflection altitude increases until, at the critical angle given in Eq. (1), the ray is reflected from the layer maximum at the minimum range from the transmitter. After being reflected, this critical-angle ray reaches the ground at the "skip distance" for the ray frequency $f_{0}$. For convenience, this ground range will be identified as $\mathrm{SF}_{0}$. The term "skip distance" is used because ionospherically propagating signals at frequency $f_{0}$ cannot reach ground ranges less than $\mathrm{SF}_{0}$ since at the required takeoff angles the constraints of Eq. (1) are not met (i.e. all such rays penetrate the ionosphere and are lost into space). As the ray frequency is increased, the skip distance also increases since rays at this higher frequency must strike the ionosphere at a more glancing angle to avoid penetrating through the layer peak. Thus, at a ground range of $\mathrm{SF}_{0}, f_{0}$ is the MUF. This relationship between the skip distance and MUF can be used to define MUF as a function of ground range, i.e. if the function relating skip distance to frequency is known, the inverse relation defines MUF as a function of ground range. The approach used here is to take advantage of this relationship by using ground-scatter returns to define the variation in skip distance with frequency, and then to obtain from this information MUF as a function of ground range.

Given a profile of backscattered power as a function of range from the radar, the skip distance for some frequency is the nearest ground range at which ground-scatter returns are observed. In the work discussed here, a virtual reflection height of $400 \mathrm{~km}$ was used when converting from radar range to ground range. It should also be noted that the conversion and other MUF calculations used here do account for the curvature of the Earth and ionosphere. Figure 1 shows the returned ground-scatter power as a function of ground range observed with the sounding mode on one beam of the Kodiak SuperDARN radar on 23 June 2001 between 22:40 and 22:55 UT. The solid lines in panels (a)-(h) show the groundscatter power observed at each of the eight sounding mode frequencies (which are identified near the upper left corner of each panel).

In some panels (e.g. panels $\mathrm{d}$ and e), more than one peak in ground-scatter power is observed; this condition occurs when more than one propagation mode is received by the radar. Most commonly (as in this case), the two peaks are due to E- and F-region propagation. Since we are primarily interested in determining MUFs for F-region propagation, it is necessary to differentiate between the two modes. This can be done by realizing that under normal ionospheric conditions, F-region returns are observed at ranges larger than those from the E-region (since F-region returns are reflected from a higher altitude) and by considering the effects of antenna gain on the ground-scatter profile. SuperDARN HF radars use arrays of log periodic dipole antennas that have a vertical-plane gain function essentially the same as that of a half-wave dipole above a ground plane. For an antenna with this gain pattern, Bristow and Greenwald (1995) show that the received ground-scatter power falls off rapidly with range due to decreasing antenna sensitivity as the incoming angle approaches the horizontal. The effects of this gain pattern can be seen in two features commonly observed in groundscatter profiles such as those shown in Fig. 1. First, the received power of ground-scatter reflected from the F-region is usually higher than that from the E-region. This is expected since F-region critical frequencies generally exceed those in the E-region, and, therefore, signals reflected from the F-region are normally received at higher incoming angles (and therefore with more antenna gain) than those reflected from the E-region. Second, when E- and F-region groundscatter returns are observed in the same profile, the rapid falloff makes it possible to identify two separate peaks. As previously mentioned, the F-region peak will occur at longer ranges than the E-region peak.

From the observed ground-scatter profiles, our algorithm automatically determines both the E- and F-region skip distances, though only the F-region skip distances will be discussed here. The algorithm first computes the best leastsquares fit of the function

$$
G=A \exp \left(-\frac{\left(x-x_{0}\right)^{2}}{w^{2}}\right) \frac{\tan ^{-1}\left(s\left(x-x_{0}\right)\right)}{\pi}+.5
$$

to the F-region ground scatter data, where $G=$ $G\left(A, x_{0}, w, s\right), x$ is ground range from the radar and $A, x_{0}$, $w$, and $s$ are parameters that are adjusted to achieve the best 


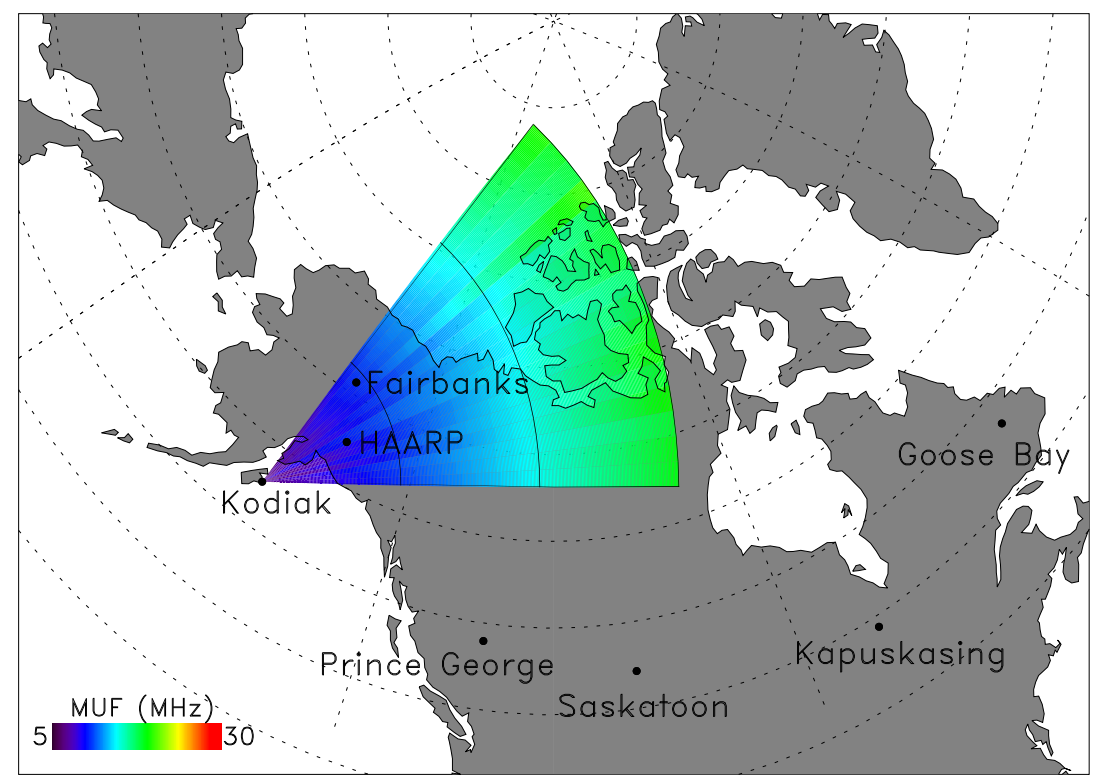

Fig. 2. Maximum usable frequency as a function of ground range over the Kodiak SuperDARN radar field-ofview obtained using ground-scatter data recorded on 23 June 2001 from 22:3922:55 UT. For any point in the field-ofview, the color scale indicates the bestfit value of MUF for HF communications between that location and the Kodiak radar site.

fit (these parameters, respectively, specify the amplitude of the fitted function, the ground distance to the peak, the distribution width, and the asymmetry about the maximum). The fitted functions $G$ are shown as dashed lines in Fig. 1. This fitting is necessary since the ground-scatter profiles are sometimes more complex than those shown in Fig. 1 and the fitted functions give a convenient measure of the profile shape. The functional form of $G$ allows for a good fit to be found both for symmetric and asymmetric ground-scatter profiles (e.g. Figs. 1c and g, respectively). The parameter $w$ gives a measure of the profile width and the parameter $s$ specifies its asymmetry. Once the best-fit function $G$ has been determined, the algorithm locates the skip distance by starting at the range corresponding to the maximum value of $G$ and moving to shorter ranges until the returned power of F-region ground-scatter signals remains below a fixed threshold. The skip distances identified using this algorithm are shown as solid vertical lines in Figs. 1a-h. Note that for the profile shown in Fig. 1h, no skip distance could be identified since virtually no ground-scatter returns were observed.

Figure 1i shows these skip distances plotted as a function of frequency. The solid line in Fig. 1i is a linear least-squares fit to the data points. Although the data points lie very close to the fitted line in this example, outlying points do occur in practice. These points are identified and rejected by the fitting routine which iteratively recomputes the fit after testing for any outlying points. As described above, inverting the function relating skip distance to frequency (which is linear over the frequency range studied here) gives an expression yielding MUF as a function of ground range from the radar. This analysis can be performed on data observed with each of the 16 radar beams to obtain MUF as a function of range over the entire radar field-of-view. Figure 2 shows MUF over the Kodiak SuperDARN radar field-of-view for the 23 June 2001 time period between 22:39 and 22:55 UT. Solid black

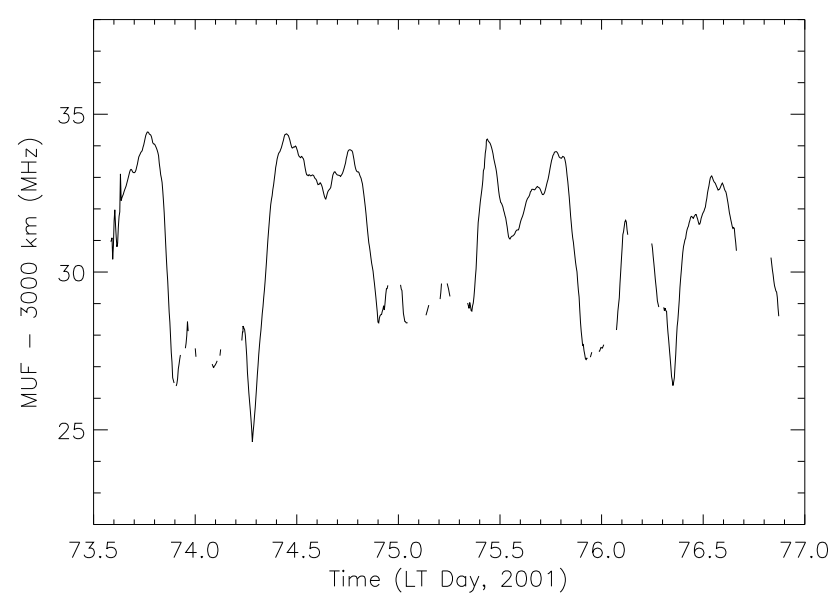

Fig. 3. Time series of MUF at $3000 \mathrm{~km}$ ground range from the Kodiak SuperDARN radar, averaged over all beams.

arcs appear at ground ranges of 1000, 2000, and $3000 \mathrm{~km}$ from the radar, and the color scale in the field-of-view indicates the best-fit value of MUF for communication between that ground location and the Kodiak radar site. In this example, MUF is fairly constant over all beam directions, with an average value of $18.5 \mathrm{MHz}$ at $3000 \mathrm{~km}$ ground range from the radar. Figure 3 shows a time series of MUF from 1417 March 2001 at $3000 \mathrm{~km}$ ground range from the Kodiak radar, averaged over all beam directions. As expected, there is an strong diurnal trend with daily MUF values increasing to a maximum near local noon and reaching a minimum near local midnight.

As previously mentioned, this method for determining MUF benefits from SuperDARN's wide spatial coverage and real-time data availability. For each SuperDARN radar running the sounding mode with real-time accessible data, MUF 


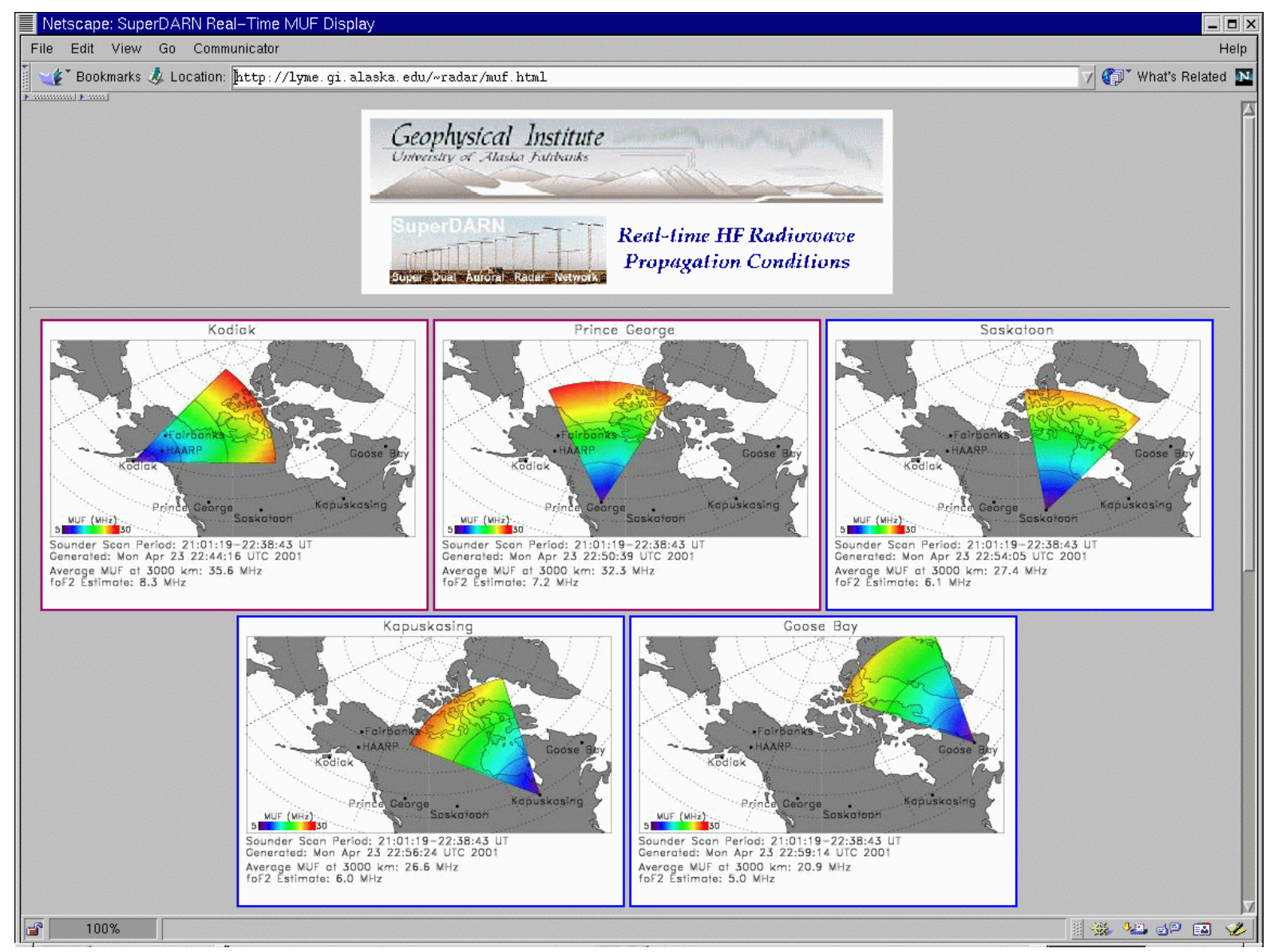

Fig. 4. World Wide Web page display using synthesized data showing near-real-time MUF and overhead ionospheric critical frequency estimates for five Northern Hemisphere SuperDARN radars. The user can activate links on this page to obtain more detailed information about each site.

over the radar field-of-view is calculated every $5 \mathrm{~min}$ and made available on the World Wide Web at http://superdarn. gi.alaska.edu. Figure 4 shows an example of the web page data display. This figure shows MUF values in the same format as Fig. 2, computed using simulated data for five Northern Hemisphere SuperDARN sites. From this web page, the user can activate links to obtain more detailed information about a particular site.

One limitation of this technique is that it requires the existence of propagation conditions which allow for HF radars to observe ground-scatter at several different frequencies in the $8-20 \mathrm{MHz}$ range. Such conditions, however, do not always exist. For example, the nighttime ionosphere is often unable to support propagation at the required frequencies (resulting in most of the data gaps shown in Fig. 3). Of course, space weather disturbances can also modify the structure of the high-latitude ionosphere and cause severe disruptions of HF communications. As an extreme example of such a disturbance, polar cap absorption (PCA) events cause complete blackouts on polar and trans-polar HF communications links. PCA events, which result from increased $D$-layer ionization following a solar proton event, are a particularly devastating type of space weather disturbance since they affect a broad frequency range and can last several days. Although the technique described here cannot be used to predict the occurrence of such events, they are easily identified in the real-time $\mathrm{Su}$ perDARN data.

\subsection{Ionospheric critical frequencies}

As mentioned earlier, signals propagating to the skip distance are reflected from the F-region peak. If either the takeoff angle or, equivalently, the F-region peak virtual height is known, skip distances measured from SuperDARN groundscatter data and an expression equivalent to Eq. (1) can then be used to calculate the vertical incidence critical frequency $(f o \mathrm{~F} 2)$ at the reflection point which can be assumed to be located at half the skip distance. Since the skip distance is dependent on both frequency and beam direction, data from SuperDARN radars can be used in this way to calculate Fregion critical frequencies at a large number of high-latitude locations.

The angle of arrival of incoming signals, which is equal to the takeoff angle, is measured by SuperDARN radars but is not available in real-time at the time of this writing (how- 


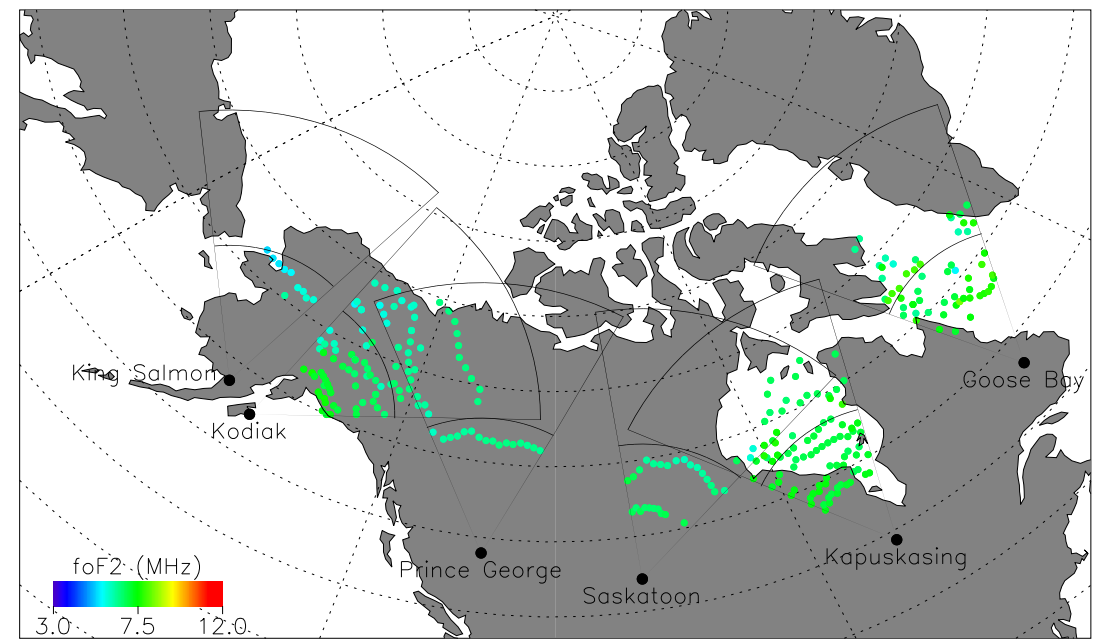

Sounder Scan Period: 00:05:41-00:20:49 UT Generated: Thu Aug 9 00:20:52 UTC 2001

Number of Data Points: 295
Fig. 5. Critical frequencies computed using real-time SuperDARN data. The colored circles show locations corresponding to half the skip distance observed for each frequency and beam direction with the color scale indicating the F-region critical frequency at that point. ever, it is planned to have this parameter available in the near future). Because of this, our real-time critical frequency analysis must make use of either a representative angle of arrival or virtual height for the F-region peak; we have assumed a virtual height of $400 \mathrm{~km}$. The effects of this assumption on the accuracy of the technique will be discussed later.

It should be noted that Eq. (1), and, therefore, our method for calculating critical frequencies only applies to a flat ionosphere. However, the effects of ionospheric curvature can often be taken into account by rewriting Eq. (1) in the form of a "modified secant law" given by $f_{0}=k f_{c} \sec \phi_{0}$, where $\phi_{0}$ is the vertical angle of the ray and $k$ is a numerical correction factor. The value of $k$ typically varies from $1-1.2$ and depends on, for example, propagation distance, the ionospheric profile and the virtual reflection height (Goodman, 1992). In this study, we have chosen to calculate critical frequencies assuming $k=1$ (i.e. the flat ionosphere approximation), an assumption supported by two main considerations. First, critical frequencies in our study are only calculated for ground ranges less than $\sim 1500 \mathrm{~km}$ and at these ranges, Goodman (1992) has shown that $k$ is nearly 1 , increasing to a maximum value of $\sim 1.04$ at $\sim 1500 \mathrm{~km}$. Second, the value of $k$ depends on the virtual reflection altitude and, as noted earlier, this parameter is not currently available in real-time for SuperDARN radars. Since it is not possible, therefore, to accurately determine $k$ in real-time, it seems reasonable to accept the errors (which should typically be less than 4\%) introduced by assuming $k=1$. Also note that since the MUF calculations discussed in the previous section take curvature into account, they are not affected by this source of error.

F-region critical frequencies are computed from the realtime data every five minutes for locations corresponding to the reflection point associated with each frequency and beam direction. For a radar running the sounding mode with, for example, 8 frequencies on each of the 16 beams, this technique allows us to calculate critical frequencies at up to 128 locations in the field-of-view (although, in practice, this limit is seldom reached). For a radar not running the sounding mode, it is still possible to calculate critical frequencies at up to one location per beam using data from the normal azimuth scan. By combining data from all SuperDARN radars, this technique makes it possible to calculate critical frequencies at many locations throughout the combined SuperDARN field-of-view.

Figure 5 shows a map of critical frequencies obtained in this way from real-time SuperDARN data recorded on $9 \mathrm{Au}-$ gust 2001 from 00:05 to 00:20 UT. During this time period, three SuperDARN radars were running the sounding mode (Kodiak, Kapuskasing, and Goose Bay) and three were performing normal azimuth scans (King Salmon, Prince George, and Saskatoon). The colored circles mark locations corresponding to half the skip distance at some frequency (which we take to be the reflection point), with the color indicating the F-region critical frequency at that location. In this example, critical frequencies were calculated at 295 points within the field-of-view of these six radars.

During times when there is no gradient in F-region critical frequency across the radar field-of-view, the distance from the radar to the reflection point will be constant as the radar scans in azimuth. Because of this, many of the data points in Fig. 5 lie on approximately concentric circles centered on the radar site (in this example, the effect is most clearly seen in the data from Prince George and Saskatoon). It should also be noted that the normal azimuth scans by the Saskatoon radar during the time period studied here were performed at two different operating frequencies. Data from these two frequencies make it possible to estimate critical frequencies at up to two locations per beam direction.

Figure 6a shows F-region critical frequencies observed near Gakona, Alaska, from 16-18 May 2001. The red line shows critical frequencies observed with the digital ionosonde located at the High-frequency Active Auroral Re- 


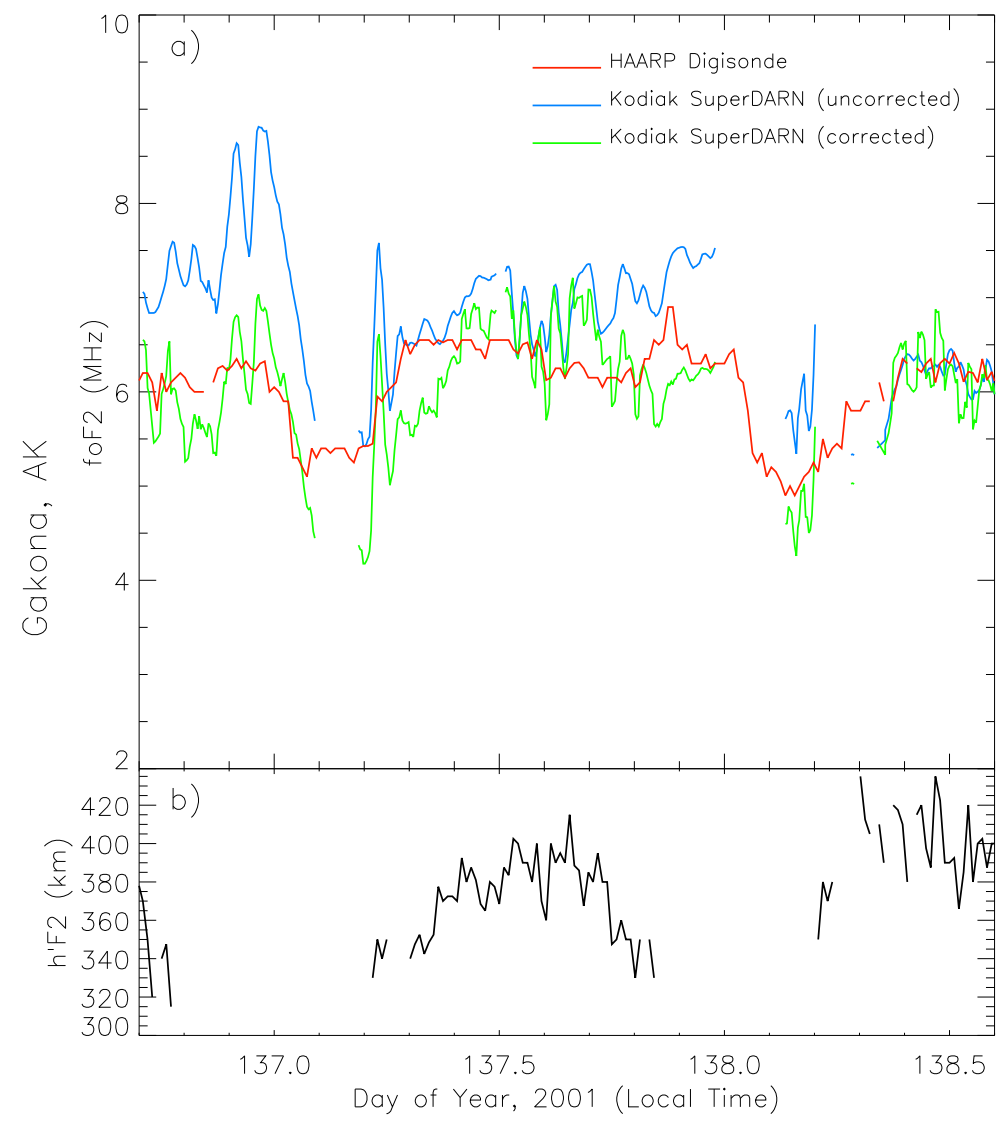

Fig. 6. (a) Critical frequencies near Gakona, Alaska measured with the HAARP digisonde (in red) and estimated from real-time SuperDARN ground-scatter data (in blue). The green curve shows the SuperDARN results after applying a correction for the variation in critical frequency with the virtual height of the F-region peak. (b) Fregion virtual heights observed with the HAARP digisonde. search Program (HAARP) site near Gakona, Alaska and the blue line shows critical frequencies calculated using realtime SuperDARN sounding mode data. The green line shows corrected SuperDARN values and will be discussed later. The SuperDARN values were obtained by identifying reflection points located within $150 \mathrm{~km}$ ground range of Gakona at the assumed virtual height of $400 \mathrm{~km}$.

As expected, each of these curves shows a diurnal trend with the lowest critical frequencies occurring during the several hours after local midnight. As in Fig. 3, the data gaps indicate time periods (mostly during nighttime hours) when the technique could not be applied. Although the real-time SuperDARN values agree fairly well in general with those measured by the digisonde, at times the disagreement is significant. Perhaps the most important source of error in this technique is the required assumption of a virtual height for the $F$-layer peak. This assumption will introduce error into the calculation whenever the actual virtual height differs from the assumed value of $400 \mathrm{~km}$.

Figure $6 \mathrm{~b}$ shows the virtual height of the $F$-layer peak obtained from ionograms recorded with the Gakona digisonde once every 15 minutes during the same time period shown in Fig. 6a. For the time period after day 138.3, the measured virtual heights are close to the assumed value and the real-time SuperDARN critical frequencies agree very well with those measured by the digisonde. However, at other times the virtual height differs significantly from the assumed value and the corresponding SuperDARN results are farther from the measured values. Using the virtual heights obtained from the digisonde, it is possible to apply a post-processing correction to the real-time SuperDARN results. The data in green in Fig. 6a show the SuperDARN critical frequencies after applying a first-order correction for the variation in critical frequency with virtual height. At times for which the measured virtual height is not available, the last available measurement has been used. These corrected values agree very well with the critical frequencies measured with the digisonde.

Uncorrected SuperDARN critical frequencies are computed in near-real-time and made available on the web display shown in Fig. 4. In this figure, the MUF plot for each site contains an estimate of the overhead critical frequency obtained by averaging all critical frequencies observed within $200 \mathrm{~km}$ ground range of the radar site. Although not shown in Fig. 4, the web display also includes the most recent critical frequency map, shown in the same format as Fig. 5.

This technique for determining F-region critical frequencies shares the same advantages and limitations as those described above for real-time MUF observations. The broad spatial coverage of the SuperDARN radars allows for critical frequencies to be calculated at locations covering a significant fraction of the high-latitude ionosphere and the real-time availability of the data makes it possible to estimate current ionospheric conditions. However, as with the technique for 
determining MUF, critical frequencies can only be calculated when ground-scatter data is available.

\section{Summary}

Space weather effects can seriously impact HF communications by changing the ionospheric environment through which the radio waves propagate. real-time data from the SuperDARN sounding mode can be used to monitor this environment by observing high-latitude propagation conditions. As shown in Figs. 1 and 2, ground-scatter returns received by SuperDARN radars can be used to determine MUF over the radar field-of-view. For each SuperDARN site running the sounding mode, these MUF maps are made available on the World Wide Web in near-real-time.

Data from the sounding mode can also be used to estimate F-region critical frequencies. Figure 6a shows that critical frequencies over Gakona, Alaska computed with SuperDARN ground-scatter data agree very well with values measured by the HAARP digisonde. Due to the wide spatial coverage of SuperDARN and the real-time availability of the data, the techniques described here for determining MUF and estimating ionospheric critical frequencies are potentially valuable tools for monitoring current space weather conditions.

\subsection{Future work}

These UPOS data products are still under development with many future improvements in view. At present, the accuracy of our real-time estimates of F-region critical frequencies is limited because the angle of arrival of incoming signals is not yet available in real-time. However, this parameter is expected to be available soon and should greatly improve the accuracy of the technique.

Other possible future improvements include estimating MUF over propagation links other than those including SuperDARN radars and extending the analysis of critical frequencies to include modeling of the bottomside ionospheric profile. Modeling the bottomside profile can be done by combining the critical frequency estimates with numerical ray tracing. For example, knowing the angle of arrival for ground-scatter signals as a function of range, ray tracing can be used to find the bottomside profile that best reproduces the observed data. Performing this ray tracing and profile fitting at many frequencies will allow for ionospheric tilts and gradients to be identified.
Acknowledgements. This work was supported by National Science Foundation grant OPP99-81866 and the US DoD University Partnering for Operational Support (UPOS) project. The authors wish to thank the Space Vehicles Directorate of the Air Force Research Laboratory for providing the digisonde data.

Topical Editor M. Lester thanks P. Dyson and M. Angling for their help in evaluating this paper.

\section{References}

Bristow, W. A. and Greenwald, R. A.: Estimating gravity wave parameters from oblique high-frequency backscatter: Modeling and analysis, J. Geophys. Res., 100, 3639-3648, 1995.

Bristow, W. A. and Greenwald, R. A.: Multiradar observations of medium-scale acoustic gravity waves using the Super Dual Auroral Radar Network, J. Geophys. Res., 101, 24 499-24 511, 1996.

Goodman, J. M.: HF communications: science and technology, Van Nostrand Reinhold, 115 Fifth Ave., New York, New York 10003, 1992.

Greenwald, R. A., Baker, K. B., Hutchins, R. A., and Hanuise, C.: An HF phased-array radar for studying small-scale structure in the high-latitude ionosphere, Radio Sci., 20, 63, 1985.

Greenwald, R. A., Baker, K. B., Dudeney, J. R., and Pinnock, M.: DARN/SuperDARN: A global view of the dynamics of highlatitude convection, Space Sci. Rev., 71, 761, 1995.

Ruohoneimi, J. M. and Baker, K. B.: Large-scale imaging of highlatitude convection with Super Dual Auroral Radar Network HF radar observations, J. Geophys. Res., 103, $20797,1998$.

Ruohoneimi, J. M., Greenwald, R. A., Baker, K. B., Villain, J.-P., Hanuise, C., and Kelly, J.: Mapping high-latitude plasma convection with coherent HF radars, J. Geophys. Res., 94, 13463 , 1989.

Ruohoneimi, J. M., Greenwald, R. A., and Baker, K. B.: HF radar observations of Pc5 field line resonances in the midnight/early morning MLT sector, J. Geophys. Res., 96, 15 697, 1991.

Samson, J. C., Greenwald, R. A., Ruohoniemi, J. M., Frey, A., and Baker, K. B.: Goose Bay radar observations of earth-reflected atmospheric gravity waves in the high-latitude ionosphere, J. Geophys. Res., 95, 7693-7709, 1990.

Samson, J. C., Wallis, D. D., Hughes, T. J., Creutzberg, F., Ruohoniemi, J. M., and Greenwald, R. A.: Substorm intensifications and field line resonances in the nightside magnetosphere, J. Geophys. Res., 97, 8495-8518, 1992.

Shepherd, S. G. and Ruohoniemi, J. M.: Electrostatic potential patterns in the high latitude ionsophere constrained by SuperDARN measurements, J. Geophys. Res., 105, 20 005, 2000.

Walker, A. D. M., Ruohoniemi, J. M., Baker, K. B., Greenwald, R. A., and Samson, J. C.: Spatial and temporal behaviour of ULF pulsations observed by the Goose Bay HF radar, J. Geophys. Res., 97, 12 187-12 202, 1992. 